\title{
Utilization of Molecular Testing and Survival Outcomes of Treatment with First- or Second-line Tyrosine Kinase Inhibitors in Advanced Non-small Cell Lung Cancer in a Dutch Population
}

\author{
ROMINA SLUGA ${ }^{1}$, BEN E.E.M. VAN DEN BORNE ${ }^{2}$, PAUL ROEPMAN ${ }^{3}$, BAS J.M. PETERS ${ }^{4}$, \\ ELISABETH A. KASTELIJN ${ }^{5}$ and FRANZ M.N.H. SCHRAMEL ${ }^{1}$ \\ Departments of ${ }^{1}$ Pulmonary Diseases, ${ }^{3}$ Pathology, and ${ }^{4}$ Clinical Pharmacy, St. Antonius Hospital, \\ Nieuwegein/Utrecht, the Netherlands/Santeon Care for Outcomes NSCLC Study Group, \\ Santeon Hospital Group, Utrecht, the Netherlands; \\ ${ }^{2}$ Department of Pulmonary Diseases, Catharina Hospital, Eindhoven, \\ the Netherlands/Santeon Care for Outcomes NSCLC Study Group, Santeon Hospital Group, Utrecht, the Netherlands; \\ ${ }^{5}$ Department of Pulmonary Diseases, Gelderse Vallei Hospital, Ede, the Netherlands
}

\begin{abstract}
Background/Aim: Epidermal growth factor receptor (EGFR) mutation testing is standard-of-care for advanced non-small cell lung cancer (NSCLC). Outcomes of second-/third-line compared to first-line tyrosine kinase inhibitors (TKIs) have shown conflicting results. We investigated utilization of molecular diagnostics and the outcomes of treatment with first-/second-line TKIs in patients with advanced NSCLC. Materials and Methods: Retrospective analysis was carried out of 2,206 patients with stage IIIb/IV NSCLC treated between 2008 and 2014 in four hospitals in the Netherlands. Results: The rate of performing molecular diagnostics increased from $20.8 \%$ to $74.4 \%$ in the study period. The median overall survival of EGFR mutationpositive patients treated with TKIs was superior compared to EGFR mutation-negative patients treated with chemotherapy (720 vs. 274 days, $p<0.0001)$. No difference in overall survival was found between EGFR mutation-positive patients treated only with TKIs compared to those treated with chemotherapy prior to TKIs, or upon progression under TKIs. Conclusion: The rate of EGFR testing has improved, increasing the number of patients eligible for targeted therapy. Chemotherapy, prior or subsequent to TKIs, for the treatment of EGFR mutation-positive patients, did not result in significantly better overall survival compared to that achieved with TKIs alone.
\end{abstract}

Correspondence to: Romina Sluga, Department of Pulmonary Diseases, St Antonius Hospital, Nieuwegein/Utrecht, Koekoekslaan 1, 3435 CM Nieuwegein, the Netherlands. E-mail: r.sluga@ antoniusziekenhuis.nl

Key Words: NSCLC, non-small cell lung cancer, EGFR, molecular testing.
Non-small cell lung cancer (NSCLC) accounts for 80-85\% of all lung cancers, with adenocarcinoma being the most common histological type (1). Treatment of metastasized disease is mostly based on platinum-based chemotherapy, but the prognosis is poor. In recent years, the development of targeted therapies, such as tyrosine kinase inhibitors (TKIs), has broadened the therapeutic options and improved prognosis of advanced lung cancer. Patients with NSCLC that harbors TKI-sensitizing mutation in epidermal growth factor receptor (EGFR, commonly exon 19 in-frame deletions or exon 21 p.L858R) and are treated with TKIs have a longer progression-free survival (PFS) and higher response rates compared to those with EGFR mutationnegative tumors treated with conventional chemotherapy (14). In addition, TKI treatment also reduces tumor burden and symptoms, and improves quality of life $(5,6)$. Furthermore, since TKIs are associated with less toxicity than conventional chemotherapy (7), they are also suitable for use in elderly and disabled patients $(5,8)$.

By not performing molecular diagnostic tests, treatment options are not fully explored, that can have a potential impact on the outcome. Routine EGFR mutation testing is therefore recommended in all patients with advanced non-squamous lung cancer or NSCLC- not otherwise specified (NOS) $(5,9)$. Although EGFR testing has been available since 2005, it only became part of the guidelines in 2011 (9). There is a lack of information on utilization of molecular diagnostic testing in patients with metastatic lung cancer. A study performed in England revealed that in 2014 only $62 \%$ were tested, showing that despite guideline recommendation, there is a large gap between provision of testing and demand (10).

Despite better response rates and longer PFS, studies so far have failed to show better overall survival (OS) 
associated with first-line TKI versus chemotherapy in patients with EGFR mutation-positive NSCLC (11), partly because a large fraction of the patients treated initially with chemotherapy crossed over to the EGFR TKI treatment arm, confounding the interpretation of overall survival data (12). Current data on treatment outcomes of second- and third-line EGFR therapy have shown conflicting results, with some suggesting tumor response rate and PFS to be similar to those with first-line therapy $(13,14)$, while others showed lower tumor response rates $(15,16)$.

Therefore, we aimed to investigate (i) the utilization of molecular diagnostic testing and (ii) the outcomes of treatment with first- or second-line TKIs compared to chemotherapy in patients with advanced NSCLC in real-world setting.

\section{Materials and Methods}

Clinical data were collected from four large teaching hospitals in the Netherlands. These four hospitals work together with two additional hospitals under the name of Santeon, a Dutch nationwide Hospital Group. Santeon serves more than $12.5 \%$ of the Dutch lung cancer patient population. The individual hospitals included in this study were: Canisius Wilhelmina Hospital (Nijmegen), Catharina Hospital (Eindhoven), Martini Hospital (Groningen), and St. Antonius Hospital (Nieuwegein/Utrecht).

In 2012, Santeon established the Care for Outcome (CfO) registry that includes outcome data from all patients diagnosed with lung and prostate cancer at any of the six hospitals from 2008 onwards. The CfO registry is built on the general Dutch Cancer Registry (managed by the Netherlands Comprehensive Cancer Organization) and subsequently enriched with clinical data from the hospitals (through extensive medical chart review and nominalizations of data). These clinical data include, amongst others, tumor characteristics, patient co-morbidities, Eastern Cooperative Oncology Group performance status (ECOG PS), treatment planning and clinical outcomes. Trained medical students supervised by a pulmonary physician extracted all items.

Since this was a retrospective study and all material was gathered as a part of routine diagnostic procedure, no written informed patient consent was required. The study was approved by the local Research Ethics Committee of each individual hospital (W16.138)

Patient selection and data collection. From the CfO database, we extracted data from all patients that were diagnosed with NSCLC from 2008 until 2014 at one of the Santeon hospitals, had clinical stage IIIB or IV (including both patients with and without systemic treatment), and had follow-up data (vitality status) available.

Information about the type of NSCLC and molecular diagnostic testing were additionally manually obtained from the electronic medical records. Patients who received chemotherapy were grouped according to the treatment received: platinum-based doublet, platinumbased doublet with pemetrexed maintenance, platinum-based doublet with bevacizumab, and TKIs. Patients were only included if malignancy had been histologically confirmed. Staging was carried out according to the seventh edition of the TNM classification (17).

Statistical analysis. Kaplan-Meier survival curves were created to present the difference in OS between different treatment arms. A
Table I. Patient characteristics.

\begin{tabular}{lc}
\hline Patient characteristics & $\mathrm{N}=2206$ \\
\hline Gender, n (\%) & $1344(60.9 \%)$ \\
Male & $862(39.1 \%)$ \\
Female & $67.4(28-98)$ \\
Age at diagnosis, years & \\
Median (range) & $682(30.9 \%)$ \\
ECOG, n (\%) & $754(34.2 \%)$ \\
0 & $366(16.6 \%)$ \\
1 & $290(11.0 \%)$ \\
2 & $114(5.2 \%)$ \\
$\geq 3$ & \\
Unknown & $583(26.4 \%)$ \\
NSCLC type, n (\%) & $1232(55.8 \%)$ \\
NOS & $390(17.7 \%)$ \\
Adenocarcinoma & \\
Squamous cell carcinoma & $256(11.6 \%)$ \\
Stage, n (\%) & $1934(87.7 \%)$ \\
3b &
\end{tabular}

ECOG: Eastern Cooperative Oncology Group performance status score, NSCLC: non-small cell lung cancer, NOS: not otherwise specified.

Cox proportional hazard model was used to compare survival among the different treatment groups and investigate the influence of age at diagnosis (continuous variable), gender and performance status. A chi-square test for trend was performed to evaluate the utilization of molecular diagnostic tests in the study period. $p$-Values of 0.05 or less were considered statistically significant. All statistical analysis was performed using SPSS (IBM SPSS Statistics for Windows, Version 22.0; IBM Corp., Armonk, NY, USA).

\section{Results}

At the participating Santeon hospitals, 2206 patients were diagnosed with advanced NSCLC (stage IIIb and IV), between Jan 1st 2008 and Dec 31st 2014. The characteristics of the patients are provided in Table I.

Molecular diagnostic tests were performed in 879 patients (39.8\% of all cases), of which 853 of patients had NSCLCNOS or adenocarcinoma, and 26 patients had a squamouscell carcinoma. Molecular diagnostic tests were performed in $10.5 \%$ of all patients diagnosed with adenocarcinoma/ NSCLC-NOS in 2008. In 2014, this percentage had increased significantly to $74.5 \%$. There were significant differences between utilization of molecular diagnostic tests between hospitals $(p<0.0001$; Figure 1).

Outcome of molecular diagnostics. For 92 out of the 879 patients $(10.5 \%)$, there was not sufficient or suitable material on which to perform molecular diagnostic testing. EGFR mutation was reported in 84 patients with adenocarcinoma or NSCLC-NOS $(10.7 \%)$ and an activating kirsten rat 


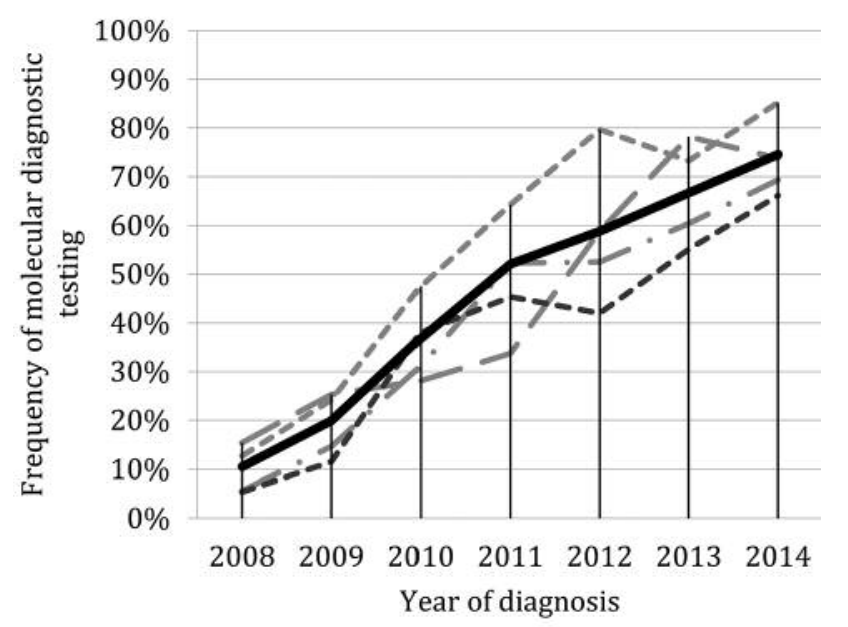

- - - Hospital 1.

- - Hospital 2.

- Hospital 3.

- - - Hospital 4.

Overall

Figure 1. Percentage of patients with adenocarcinoma/non-small cell lung cancer, not otherwise specified with molecular diagnostic tests performed according to year of diagnosis.

sarcoma viral oncogene homolog (KRAS) mutation (typically in codons 12,13 or 61 ) was found in 290 patients (36.8\%). As expected, all tumors harboring a KRAS mutation were wild-type for $E G F R$. A TKI-sensitizing $E G F R$ mutation was observed for 75 patients, with most commonly an exon 19 in-frame deletion $(\mathrm{n}=41,48.8 \%)$ or an exon 21 activating mutation $(\mathrm{n}=31,36.9 \%)$ (Table III). Nine patients $(10.7 \%)$ had a mutation in exon 20 (p.T790M or in-frame insertion) considered to be resistant/non-responder mutations.

Characteristics of patients with EGFR-mutated lung cancer are shown in Table II.

Treatment of EGFR mutation-positive patients. Of the patients with a TKI-sensitizing EGFR mutation (in exon 18, 19 or 21), the great majority $(90.7 \%)$ were treated with TKIs (Table III). Thirty-two $(42.6 \%)$ patients received only TKIs (gefitinib, erlotinib or afatinib), whereas $16(21.3 \%)$ and $20(26.7 \%)$ were treated with second-line TKIs after chemotherapy or chemotherapy after progression under TKIs, respectively.

Seven patients with sensitizing EGFR mutations received no treatment because of their low performance status $(n=3)$, refusal of treatment $(n=3)$ or rapid disease progression $(n=1)$.

Out of the patients with a resistant/non-responder $E G F R$ exon 20 mutation $(n=9)$, four were treated with conventional
Table II. Characteristics of patients with epidermal growth factor receptor (EGFR)-mutated tumors

\begin{tabular}{|c|c|}
\hline Characteristic & $\mathrm{N}=84$ \\
\hline \multicolumn{2}{|l|}{ Gender, n (\%) } \\
\hline Male & $34(40.5 \%)$ \\
\hline Female & $50(59.5 \%)$ \\
\hline \multicolumn{2}{|l|}{ Smoking status, $\mathrm{n}(\%)$} \\
\hline Non-smoker & $33(39.3 \%)$ \\
\hline Ex/current light smoker $<20$ py & $42(50 \%)$ \\
\hline Ex/current heavy/moderate smoker $<20$ py & $9(10.7 \%)$ \\
\hline \multicolumn{2}{|l|}{ Age at diagnosis, years } \\
\hline Median (range) & $64(29-86)$ \\
\hline \multicolumn{2}{|l|}{ ECOG PS, n $(\%)$} \\
\hline 0 & $41(48.8 \%)$ \\
\hline 1 & $29(34.5 \%)$ \\
\hline$\geq 2$ & $13(15.5 \%)$ \\
\hline Missing data & $1(1.2 \%)$ \\
\hline \multicolumn{2}{|l|}{ Tumor stage, n (\%) } \\
\hline 4 & $83(98.8 \%)$ \\
\hline $3 b$ & $1(4.7 \%)$ \\
\hline \multicolumn{2}{|l|}{ EGFR exon, $\mathrm{n}(\%)$} \\
\hline Exon 18 (e.g. G719X) & $3(3.6 \%)$ \\
\hline Exon 19 (in frame deletions) & $41(48.8 \%)$ \\
\hline Exon 20 (e.g. $T 790 M$ and-in frame insertions) & $9(10.7 \%)$ \\
\hline Exon 21 (e.g. L858R, L861Q) & $31(36.9 \%)$ \\
\hline \multicolumn{2}{|l|}{ Treatment according to mutation, $\mathrm{n}(\%)$} \\
\hline \multicolumn{2}{|l|}{$E G F R$ exon $18,19,21(\mathrm{n}=75)$} \\
\hline No treatment & $7(9.3 \%)$ \\
\hline Only TKIs & $32(42.6 \%)$ \\
\hline Chemotherapy before TKIs & $16(21.3 \%)$ \\
\hline Chemotherapy after TKIs & $20(26.7 \%)$ \\
\hline \multicolumn{2}{|l|}{$E G F R$ e $20(\mathrm{n}=9)$} \\
\hline No treatment & $2(22.2 \%)$ \\
\hline Chemotherapy & $4(44.4 \%)$ \\
\hline Chemotherapy before TKIs & $2(22.2 \%)$ \\
\hline TKIs before chemotherapy & $1(11.1 \%)$ \\
\hline
\end{tabular}

ECOG: Eastern Cooperative Oncology Group performance status score, TKI: tyrosine kinase inhibitor, py: pack-years.

chemotherapy because of expected poor response to TKIs, two received no treatment, two were treated with chemotherapy before TKIs and one patient was treated with TKIs before chemotherapy (Table III).

Overall survival. The median OS adjusted for age, gender and performance status was 720 days $(95 \%$ confidence interval (CI) $=641-911$ days) in $E G F R$ mutation-positive patients (sensitizing mutations only, excluding exon 20 mutations) treated with TKIs (with or without prior/subsequent chemotherapy) versus 274 days (95\% $\mathrm{CI}=385-452$ days) in patients without $E G F R$ mutations treated with conventional chemotherapy $(p<0.0001)$ (Table III, Figures 2 and 3). Further analysis of this patient group indicated no statistically significant differences in OS 


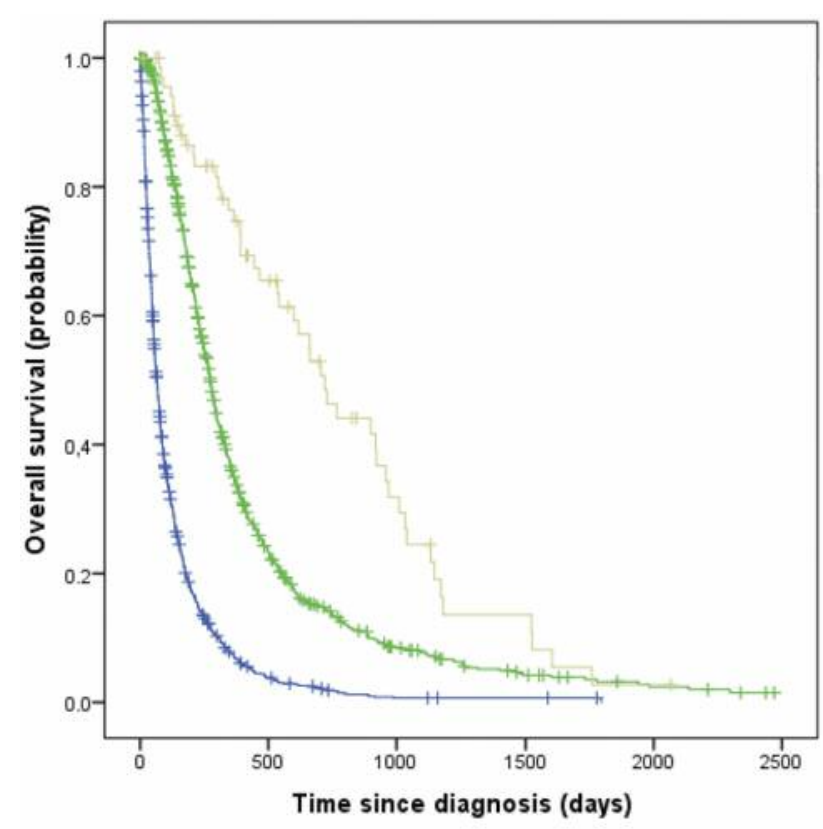

IIEGFR", no therapy $\neg \mathrm{EGFR}^{+}$, convention chemotherapy

Figure 2. Kaplan-Meier curves presenting overall survival in patients without epidermal growth factor receptor (EGFR) mutations and no treatment [median $=66$ days, 95\% confidence interval $(\mathrm{CI})=60-72$ days], without EGFR mutation treated with conventional chemotherapy (median=274 days, 95\% CI=385-452 days), and with an EGFR mutation treated with tyrosine kinase inhibitors (TKIs) with or without prior/subsequent chemotherapy (median $=720$ days, $95 \%$ CI=641-911 days).

between the different treatment regimens: median OS of 1034 (95\% CI=703-1285) days for those treated with conventional chemotherapy before TKI; 704 (95\% CI=581961) days for those treated with TKIs followed by chemotherapy; and 599 (95\% CI=455-760) days for those treated only with TKIs (Table III). There was no evidence that survival was related to age at diagnosis $(p=0.14)$, gender $(p=0.43)$ or ECOG PS $(p=0.26)$.

Re-biopsy after progression of disease. Out of 84 patients with an initial EGFR-sensitizing mutation, 13 patients (15.5\%) underwent a biopsy to evaluate the potential development of an exon 20 resistant mutation after progression on TKI. For one patient, no reliable result could be generated because of inappropriate material. The majority of patients with progressive disease $(\mathrm{n}=8)$ developed the well-known EGFR p.T790M resistance mutation. Four out of these eight patients with $E G F R$ T790M continued treatment with third-generation TKI (osimertinib). In four patients, only the initial sensitizing mutations (in exon 19 and 21) were found, without any sign of an exon 20 mutation.

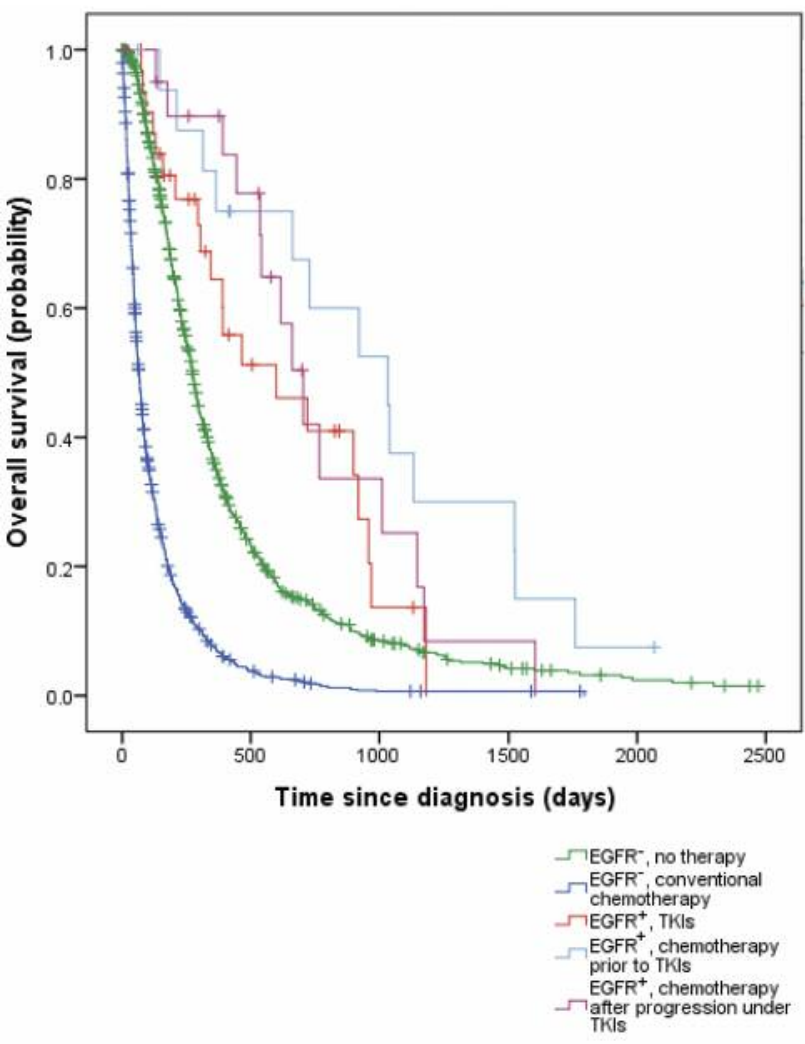

Figure 3. Kaplan-Meier curves presenting overall survival in patients without epidermal growth factor receptor (EGFR) mutations and no treatment [median $=66$ days, 95\% confidence interval $(C I)=60-72$ days], without EGFR mutation treated with conventional chemotherapy (median=274 days, 95\% CI=385-452 days), with EGFR sensitizing mutations treated with tyrosine kinase inhibitors (TKIs) only (median=599 days, 95\% CI=455-760 days), with EGFR sensitizing mutations treated with conventional chemotherapy after progression under TKIs (median=704 days, 95\% CI=581-961 days), and with EGFR sensitizing mutations treated with chemotherapy before TKIs (median $=850$ days, 95\% CI=174-1524 days).

\section{Discussion}

This study showed that the utilization of molecular testing has improved significantly over the years, leading to more effective targeted therapies. The median OS in patients with EGFR mutations treated with TKIs (with or without prior/subsequent) chemotherapy was longer than that for $E G F R$ mutation-negative patients treated with conventional chemotherapy. Although EGFR mutation-positive patients treated with chemotherapy prior to TKIs tended to have the longest OS, partly because of the small number of patients, no statistically significant survival benefit was shown.

By not performing molecular diagnostics, patients cannot be considered for targeted therapy. Therefore, it is important to assess the extent to which these tests are being utilized. 
Table III. Mean survival according to epidermal growth factor receptor (EGFR) mutation and treatment type.

\begin{tabular}{|c|c|c|}
\hline Treatment type according to targetable mutation & Median survival (days) & $95 \%$ CI (days) \\
\hline \multicolumn{3}{|l|}{$E G F R$-negative } \\
\hline No treatment $(\mathrm{N}=1168)$ & 66 & $60-72$ \\
\hline Chemotherapy (N=932) & 274 & $385-452$ \\
\hline \multicolumn{3}{|l|}{ EGFR-positive-exon 18,19 or 21 (sensitizing mutations) $(\mathrm{N}=75)$} \\
\hline No treatment $(\mathrm{N}=7)$ & 121 & $74-138$ \\
\hline TKI treatment (all types) $(\mathrm{N}=68)$ & 720 & $641-911$ \\
\hline Only TKI (N=32) & 599 & $455-760$ \\
\hline Chemotherapy before TKI $(\mathrm{N}=16)$ & 1034 & $703-1285$ \\
\hline TKI followed by conventional chemotherapy $(\mathrm{N}=20)$ & 704 & $581-961$ \\
\hline EGFR-positive- exon 20 (resistance/non-responding mutations) $(\mathrm{N}=9)$ & 165 & $0.4-329.6$ \\
\hline No treatment $(\mathrm{N}=2)$ & 71 & $42-100$ \\
\hline Chemotherapy $(\mathrm{N}=4)$ & 248 & $123-398$ \\
\hline Chemotherapy before TKIs $(\mathrm{N}=2)$ & 850 & $174-1524$ \\
\hline TKIs before chemotherapy $(\mathrm{N}=1)$ & 13 & \\
\hline
\end{tabular}

TKI: Tyrosine kinase inhibitor; CI: confidence interval.

EGFR testing has been available since 2005, however specific recommendations for EGFR mutation analysis in stage IIIb and IV adenocarcinoma and NSCLC-NOS only became a part of the Dutch guidelines in 2011 (9). Underutilization before 2011 was therefore expected. Nevertheless, only 63\% of patients were tested in the period of study here, meaning 403 (37\%) patients were missing out on molecular diagnostic tests. Surprisingly, despite comparable hospital characteristics, there were also significant institutional differences in utilization of EGFR assays. The incidence of molecular diagnostic testing did however improve significantly between 2011 and 2014, increasing from $52.1 \%$ in 2011 to $74.5 \%$ in 2014 (Figure 1). A study performed on the frequency of molecular diagnostic testing in England showed an even larger gap between provision of testing and demand, with only $62 \%$ being tested in 2014 (10).

EGFR mutations were found for $10.7 \%$ of all patients tested in our cohort, which is in line with other studies performed on other European populations, with incidence ranging from $9.1 \%$ to $16.6 \%(13,18,19)$.

Not only can obtaining a tissue sample be challenging, often (in our case $10.5 \%$ ) these samples contain too few tumor cells to allow reliable molecular testing. (20) Since patients with advanced NSCLC have a limited life expectancy and molecular diagnostic tests are timeconsuming, practitioners tend to start treatment before mutation test results are available (21). In 2016, the U.S. Food and Drug Administration approved the first liquid biopsy test for EGFR mutation in NSCLC (cobas EGFR Mutation Test v2) (22), which allows a sample to be obtained in a minimally invasive way and is less time-consuming, which might lead to improvement of utilization of molecular diagnostic tests in the future (23).
Despite high initial response to EGFR-TKIs, most patients with sensitizing EGFR mutation eventually acquire resistance to $E G F R$ TKI therapy, by developing secondary mutations such as the T790M mutation in exon 20 (approximately 50\%) or amplification of mesenchymal epithelial transition (MET) ( 20\%) (24). Since 2015, osimertinib, an irreversible EGFR TKI selective for both EGFR-mutated and T790M resistance mutations (25), has been recommended for treatment of patients with T790Mpositive advanced NSCLC after progression with prior EGFR-TKI therapy (5). Due to a variety of resistance mechanisms and availability of targeted therapy for the most commonly (acquired) mutation, post-treatment biopsies at the time that clinical resistance to EGFR TKIs develops are therefore beneficial in selecting the most appropriate treatment (26). Although, our study was performed in the period when osimertinib was not yet recommended for patients with T790M mutation, 13 patients (15.5\%) with EGFR mutation underwent rebiopsy after progression to evaluate T790M mutation, and the majority (four out of the six patients who developed EGFRe 20 T790M mutation) were also treated with osimertinib.

In the first randomized clinical trial, the Iressa Pan-Asia Study or IPASS, conducted on an East Asian population, comparing gefitinib with carboplatin/paclitaxel in EGFR mutation-positive patients, showed significantly longer PFS in patients treated with gefitinib versus those treated with carboplatin/paclitaxel (9.5 vs. 6.3 months, respectively). Median OS was 18.6 months among patients receiving gefitinib and 17.3 months among patients receiving carboplatin-paclitaxel. (12). Studies that followed (NEJ002, WJTOG3405, EURTAC, OPTIMAL, LUX LuNG3, LUXLUNG6) confirmed the positive effect of TKIs on EGFR- 
mutated tumors for PFS $(1-4,8,27)$. These studies, however, failed to show better OS, partly because a large fraction of the patients with EGFR-mutated tumors treated initially with chemotherapy crossed over to the EGFR TKI treatment arm, confounding the interpretation of overall survival data (12). This raises the question whether chemotherapy prior to TKIs or subsequently affects the treatment outcome. It is not yet well understood if systemic therapy influences the expression of different biomarkers such as EGFR mutation in tumor (28).

Studies comparing first- and second-line EGFR therapy are limited. Chemotherapy may affect EGFR mutations status by reducing the frequency of EGFR mutations (29), suggesting reduced efficacy of second-line treatment with TKIs. A meta-analysis of 13 randomized trials showed that the response rate of TKI treatment in the first-line trials was $70 \%$, while in in second-line trials, it was $47.4 \%$, it did, however, failed to improve OS (30).

Studies advocating second- or third-line EGFR TKIs showed inconsistent results. A single-arm phase II study conducted in Spain suggested that second- or third-line EGFR TKI could attain tumor response rates and PFS similar to those of first-line therapy $(31,32)$. A randomized phase 3 trial on chemo-naive East Asian patients with advanced pulmonary adenocarcinoma, comparing first-line pemetrexed plus cisplatin followed by gefitinib maintenance therapy with gefitinib monotherapy, failed to show any significant difference in PFS in the EGFR-mutation subgroup (33).

In our cohort, EGFR mutation-positive patients treated with TKIs (without additional chemotherapy) had a significant OS benefit compared to EGFR mutation-negative patients treated with chemotherapy (599 vs. 274 days). The OS of EGFR mutation-positive patients treated with TKIs (Table III, Figure 2) was comparable to those of other studies performed on European cohorts, such as the FIELT study with a median OS of 23 months (34), and the EURTAC study with a median OS of 19.3 months (1). Despite potential toxicity related to chemotherapy possibly resulting in taking away the opportunity to receive second-line therapy (32), our patients treated with TKIs in the second line had the longest OS (34 months). OS in patients treated with second-line chemotherapy after progression under TKIs (23.1 months) and those only treated with TKIs (19.7 months) seemed inferior but no statistical significance was shown. The number of patients with EGFR-mutated tumors was probably too small to draw any significant conclusions. Furthermore, EGFR mutation heterogeneity could perhaps explain the mixed response leading to a wide CI.

Since obtaining the appropriate material for molecular diagnostics can be challenging, results suggest that starting chemotherapy while waiting for results of the EGFR mutation testing could result in promptness of therapy without compromising the OS.
Strengths and limitations. To our knowledge, no previous studies gave insight into the treatment outcomes of first- and second-line TKI compared to chemotherapy in such a long study period in real-word setting in an European cohort. While previous studies failed to show any significant OS benefit of TKIs when compared to chemotherapy, this study did manage to show that OS of patients with EGFR mutation-positive disease treated with TKIs (even without subsequent or prior chemotherapy) patients was longer than OS of EGFR mutation-negative patients treated with chemotherapy.

Since most studies have been performed in predominantly Asian cohorts, this study helps to further clarify outcomes of treatment in European patients.

The low number of patients harboring EGFR mutation is a limitation of this study, and was partly responsible for a large CI for the first- and second-line treatment groups.

Unfortunately, we had no information available about the PFS and were unable to analyze the effect of first- or secondline treatment with TKI on PFS.

\section{Conclusion}

Incidence of molecular diagnostic testing has improved significantly, leading to more effective targeted therapy. Treatment with TKIs in patients with EGFR-mutated tumors with or without prior/subsequent chemotherapy led to better OS than that of patients with EGFR mutation-negative tumors treated with chemotherapy. Chemotherapy, prior to TKIs or subsequently, did not result in significantly better OS compared to therapy with TKIs alone.

\section{References}

1 Rosell R, Carcereny E, Gervais R, Vergnenegre A, Massuti B, Felip E, Palmero R, Garcia-Gomez R, Pallares C, Sanchez JM, Porta R, Cobo M, Garrido P, Longo F, Moran T, Insa A, De Marinis F, Corre R, Bover I, Illiano A, Dansin E, de Castro J, Milella M, Reguart N, Altavilla G, Jimenez U, Provencio M, Moreno MA, Terrasa J, Muñoz-Langa J, Valdivia J, Isla D, Domine M, Molinier O, Mazieres J, Baize N, Garcia-Campelo R, Robinet G, RodriguezAbreu D, Lopez-Vivanco G, Gebbia V, Ferrera-Delgado L, Bombaron P, Bernabe R, Bearz A, Artal A, Cortesi E, Rolfo C, Sanchez-Ronco M, Drozdowskyj A, Queralt C, de Aguirre I, Ramirez JL, Sanchez JJ, Molina MA, Taron M and Paz-Ares L: Erlotinib versus standard chemotherapy as first-line treatment for European patients with advanced EGFR mutation-positive nonsmall-cell lung cancer (EURTAC): a multicentre, open-label, randomised phase 3 trial. Lancet Oncol 13: 239-246, 2012.

2 Sequist L V, Yang JC, Yamamoto N, O’Byrne K, Hirsh V, Mok T, Geater SL, Orlov S, Tsai CM, Boyer M, Su WC, Bennouna J, Kato T, Gorbunova V, Lee KH, Shah R, Massey D, Zazulina V, Shahidi M and Schuler M: Phase III study of afatinib or cisplatin plus pemetrexed in patients with metastatic lung adenocarcinoma with EGFR mutations. J Clin Oncol 31: 3327$3334,2013$. 
3 Wu Y-L, Zhou C, Hu C-P, Feng J, Lu S, Huang Y, Li W, Hou M, Shi JH, Lee KY, Xu C-R, Massey D, Kim M, Shi Y and Geater SL: Afatinib versus cisplatin plus gemcitabine for firstline treatment of Asian patients with advanced non-small-cell lung cancer harbouring EGFR mutations (LUX-Lung 6): an open-label, randomised phase 3 trial. Lancet Oncol 15: 213-222, 2014.

4 Zhou C, Wu Y-L, Chen G, Feng J, Liu X-Q, Wang C, Zhang S, Wang J, Zhou S, Ren S, Lu S, Zhang L, Hu C, Hu C, Luo Y, Chen L, Ye M, Huang J, Zhi X, Zhang Y, Xiu Q, Ma J, Zhang L and You C: Erlotinib versus chemotherapy as first-line treatment for patients with advanced EGFR mutation-positive non-smallcell lung cancer (OPTIMAL, CTONG-0802): a multicentre, open-label, randomised, phase 3 study. Lancet Oncol 12: 735742,2011

5 Ettinger DS, Wood DE, Akerley W, Bazhenova LA, Borghaei H, Camidge DR, Cheney RT, Chirieac LR, D'Amico TA, Dilling TJ, Dobelbower MC, Govindan R, Hennon M, Horn L, Jahan TM, Komaki R, Lackner RP, Lanuti M, Lilenbaum R, Lin J, Loo Jr. BW, Martins R, Otterson GA, Patel JD, Pisters KM, Reckamp K, Riely GJ, Schild SE, Shapiro TA, Sharma N, Stevenson J, Swanson SJ, Tauer K, Yang SC, Gregory K and Hughes M: NCCN Guidelines Insights: Non-Small Cell Lung Cancer, Version 4.2016. J Natl Compr Canc Netw 14: 255-264, 2016.

6 Inoue A, Kobayashi K, Usui K, Maemondo M, Okinaga S, Mikami I, Ando M, Yamazaki K, Saijo Y, Gemma A, Miyazawa H, Tanaka T, Ikebuchi K, Nukiwa T, Morita S and Hagiwara K: First-line gefitinib for patients with advanced non-small-cell lung cancer harboring epidermal growth factor receptor mutations without indication for chemotherapy. J Clin Oncol 27: 1394-1400, 2009.

7 Arora A and Scholar EM: Role of tyrosine kinase inhibitors in cancer therapy. J Pharmacol Exp Ther 315: 971-979, 2005.

8 Maemondo M, Inoue A, Kobayashi K, Sugawara S, Oizumi S, Isobe H, Gemma A, Harada M, Yoshizawa H, Kinoshita I, Fujita Y, Okinaga S, Hirano H, Yoshimori K, Harada T, Ogura T, Ando M, Miyazawa H, Tanaka T, Saijo Y, Hagiwara K, Morita S and Nukiwa T: Gefitinib or chemotherapy for non-small-cell lung cancer with mutated EGFR. N Engl J Med 362: 2380-2388, 2010 .

9 De Vereniging van Integrale Kankercentra (VIKC): Nietkleincellig longcarcinoom. Landelijke richtlijn, Versie: 2.0. Versie:2.0, 2011.

10 Don-Carolis J and Candeto J: Molecular diagnostic provision in the NHS in England For Targeted Cancer Medicines (solid tumors) in the NHS. Concentra Analytics. http://www.cancerresearchuk.org/ sites/default/files/policy_august2015_mdx_final.pdf, 2015, last accessed 24/10/2017.

11 Green JA, Bates V, Greenhalgh J, Boland A, Jain P, Dickson RC, Dwan $\mathrm{K}$ and Vecchio F: First-line treatment of advanced epidermal growth factor receptor (EGFR) mutation-positive nonsquamous non-small cell lung cancer (protocol). Cochrane Database Syst Rev 2013: CD010383, 2013.

12 Mok TS, Wu YL, Thongprasert S, Yang CH, Chu DT, Saijo N, Sunpaweravong P, Han B, Margono B, Ichinose Y, Nishiwaki Y, Ohe Y, Yang JJ, Chewaskulyong B, Jiang H, Duffield EL, Watkins CL, Armour AA and Fukuoka M: Gefitinib or carboplatin-paclitaxel in pulmonary adenocarcinoma. N Engl J Med 361: 947-957, 2009.
13 Rosell R, Moran T, Queralt C, Porta R, Cardenal F, Camps C, Majem M, Lopez-Vivanco G, Isla D, Provencio M, Insa A, Massuti B, Gonzalez-Larriba JL, Paz-Ares L, Bover I, Garcia-Campelo R, Moreno MA, Catot S, Rolfo C, Reguart N, Palmero R, Sánchez JM, Bastus R, Mayo C, Bertran-Alamillo J, Molina MA, Sanchez JJ and Taron M: Screening for epidermal growth factor receptor mutations in lung cancer. N Engl J Med 361: 958-967, 2009.

14 Douillard J-Y, Shepherd F a, Hirsh V, Mok T, Socinski M a, Gervais R, Liao M-L, Bischoff H, Reck M, Sellers M V, Watkins CL, Speake G, Armour A and Kim ES: Molecular predictors of outcome with gefitinib and docetaxel in previously treated nonsmall-cell lung cancer: data from the randomized phase III INTEREST trial. J Clin Oncol 28: 744-752, 2010.

15 Taron M, Ichinose Y, Rosell R, Mok T, Massuti B, Zamora L, Mate JL, Manegold C, Ono M, Queralt C, Jahan T, Sanchez JJ, SanchezRonco M, Hsue V, Jablons D, Sanchez JM and Moran T: Activating mutations in the tyrosine kinase domain of the epidermal growth factor receptor are associated with improved survival in gefitinibtreated chemorefractory lung adenocarcinomas. Clin Cancer Res 11: 5878-5885, 2005.

16 Tsao M, Sakurada A and Cutz J: Erlotinib in lung cancermolecular and clinical predictors of outcome. N Engl J Med 353(2): 133-144, 2005.

17 Sobin L, Gospodarowicz $M$ and Wittekind C: TNM Classification of Malignant Tumours, Seventh Edition. Wiley, 2009. Available from: http://eu.wiley.com/WileyCDA/Wiley Title/productCd-1444332414.html

18 Marchetti A, Martella C, Felicioni L, Barassi F, Salvatore S, Chella A, Camplese PP, Iarussi T, Mucilli F, Mezzetti A, Cuccurullo F, Sacco R and Buttitta F: EGFR mutations in nonsmall-cell lung cancer: Analysis of a large series of cases and development of a rapid and sensitive method for diagnostic screening with potential implications on pharmacologic treatment. J Clin Oncol 23: 857-865, 2005.

19 Smits AJJ, Kummer JA, Hinrichs JWJ, Herder GJM, ScheidelJacobse KC, Jiwa NM, Ruijter TEG, Nooijen PTGA, LooijenSalamon MG, Ligtenberg MJL, Thunnissen FB, Heideman DAM, De Weger RA and Vink A: EGFR and KRAS mutations in lung carcinomas in the Dutch population: Increased $E G F R$ mutation frequency in malignant pleural effusion of lung adenocarcinoma. Cell Oncol 35: 189-196, 2012.

20 Korpanty G and Leighl NB: Challenges in NSCLC molecular testing. Barriers to implementation. Oncol Exch 11: 8-10, 2012.

21 Spicer J, Tischer B and Peters M: EGFR mutation testing and oncologist treatment choice in advanced NSCLC: global trends and differences. Ann Oncol 26(suppl1): i57-i61, 2015.

22 Cobas EGFR Mutation Test v2. (2016, June). Retrieved from: https://www.fda.gov/Drugs/InformationOnDrugs/ApprovedDrugs /ucm504540.htm.

23 Kwapisz D: The first liquid biopsy test approved. Is it a new era of mutation testing for non-small cell lung cancer? Ann Transl Med 5: 46-46, 2017.

24 Costa DB, Nguyen KSH, Cho BC, Sequist LV, Jackman DM, Riely GJ, Yeap BY, Halmos B, Kim JH, Janne PA, Huberman MS, Pao W, Tenen DG and Kobayashi S: Effects of erlotinib in $E G F R$-mutated non-small cell lung cancers with resistance to gefitinib. Clin Cancer Res 14: 7060-7067, 2008.

25 Cross DAE, Ashton SE, Ghiorghiu S, Eberlein C, Nebhan CA, Spitzler PJ, Orme JP, Finlay MR V, Ward RA, Mellor MJ, Hughes G, Rahi A, Jacobs VN, Brewer MR, Ichihara E, Sun J, 
Jin H, Ballard P, Al-Kadhimi K, Rowlinson R, Klinowska T, Richmond GHP, Cantarini M, Kim DW, Ranson MR and Pao W: AZD9291, an irreversible EGFR TKI, overcomes T790Mmediated resistance to EGFR inhibitors in lung cancer. Cancer Discov 4: 1046-1061, 2014.

26 Sequist L V, Waltman BA, Dias-Santagata D, Digumarthy S, Turke AB, Fidias P, Bergethon K, Shaw AT, Gettinger S, Cosper AK, Akhavanfard S, Heist RS, Temel J, Christensen JG, Wain JC, Lynch TJ, Vernovsky K, Mark EJ, Lanuti M, Iafrate AJ, Mino-Kenudson $M$ and Engelman JA: Genotypic and histological evolution of lung cancers acquiring resistance to EGFR inhibitors. Sci Transl Med 3: 75ra26, 2011.

27 Mitsudomi T, Morita S, Yatabe Y, Negoro S, Okamoto I, Tsurutani J, Seto T, Satouchi M, Tada H, Hirashima T, Asami K, Katakami N, Takada M, Yoshioka H, Shibata K, Kudoh S, Shimizu E, Saito H, Toyooka S, Nakagawa K and Fukuoka M: Gefitinib versus cisplatin plus docetaxel in patients with nonsmall-cell lung cancer harbouring mutations of the epidermal growth factor receptor (WJTOG3405): an open label, randomised phase 3 trial. Lancet Oncol 11: 121-128, 2010.

28 Remon $\mathrm{J}$ and Majem M: EGFR mutation heterogeneity and mixed response to EGFR tyrosine kinase inhibitors of non small cell lung cancer: a clue to overcoming resistance. Transl lung cancer Res 2: 445-448, 2013.

29 Bai H, Wang Z, Chen K, Zhao J, Lee JJ, Wang S, Zhou Q, Zhuo M, Mao L, An T, Duan J, Yang L, Wu M, Liang Z, Wang Y, Kang $\mathrm{X}$ and Wang $\mathrm{J}$ : Influence of chemotherapy on EGFR mutation status among patients with non-small-cell lung cancer. J Clin Oncol 30: 3077-3083, 2012.

30 Petrelli F, Borgonovo K, Cabiddu M and Barni S: Efficacy of EGFR tyrosine kinase inhibitors in patients with EGFR-mutated non-small cell-lung cancer: a meta-analysis of 13 randomized trials. Clin Lung Cancer 13: 107-114, 2011.
31 Rosell R, Moran T, Queralt C, Porta R, Cardenal F, Camps C, Majem M, Lopez-Vivanco G, Isla D, Provencio M, Insa A, Massuti B, Gonzalez-Larriba JL, Paz-Ares L, Bover I, GarciaCampelo R, Moreno MA, Catot S, Rolfo C, Reguart N, Palmero R, Sanchez JM, Bastus R, Mayo C, Bertran-Alamillo J, Molina MA, Sanchez JJ, Taron M and Spanish Lung Cancer G: Screening for epidermal growth factor receptor mutations in lung cancer. N Engl J Med 361: 958-967, 2009.

32 Mok T, Yang JJ and Lam KC: Treating patients with EGFRsensitizing mutations: First line or second line - Is there a difference? J Clin Oncol 31: 1081-1088, 2013.

33 Yang JC-H, Kang JH, Mok T, Ahn M-J, Srimuninnimit V, Lin C-C, Kim D-W, Tsai C-M, Barraclough H, Altug S, Orlando M and Park K: First-line pemetrexed plus cisplatin followed by gefitinib maintenance therapy versus gefitinib monotherapy in East Asian patients with locally advanced or metastatic nonsquamous non-small cell lung cancer: A randomised, phase 3 trial. Eur J Cancer 50: 2219-2230, 2014.

34 De Grève J, Van Meerbeeck J, Vansteenkiste JF, Decoster L, Meert A-P, Vuylsteke P, Focan C, Canon J-L, Humblet Y, Berchem G, Colinet B, Galdermans D, Bosquée L, Vermeij J, Dewaele A, Geers C, Schallier D and Teugels E: Prospective evaluation of first-line erlotinib in advanced non-small cell lung cancer (NSCLC) carrying an activating EGFR mutation: a multicenter academic phase II study in Caucasian patients (FIELT). PLoS One 11: e0147599, 2016.

Received October 1, 2017

Revised October 23, 2017

Accepted October 26, 2017 